\title{
Factors associated with provision of smoking cessation support to pregnant women - a cross-sectional survey of midwives in New South Wales, Australia
}

Megan E. Passey ${ }^{1 *}$, Jo M. Longman ${ }^{1}$, Catherine Adams², Jennifer J. Johnston ${ }^{1}$, Jessica Simms ${ }^{1}$ and Margaret Rolfe ${ }^{1}$

\begin{abstract}
Background: Smoking is the most important preventable cause of adverse pregnancy outcomes, but provision of smoking cessation support (SCS) to pregnant women is poor. We examined the association between midwives' implementation of SCS (5As - Ask, Advise, Assess, Assist, Arrange follow-up) and reported barriers/enablers to implementation.

Methods: On-line anonymous survey of midwives providing antenatal care in New South Wales (NSW), Australia, assessing provision of the $5 \mathrm{As}$ and barriers/enablers to their implementation, using the Theoretical Domains Framework (TDF). Factor analyses identified constructs underlying the 5As; and barriers/enablers. Multivariate general linear models examined relationships between the barrier/enabler factors and the 5 As factors.

Results: Of 750 midwives invited, 150 (20\%) participated. Respondents more commonly reported Asking and Assessing than Advising, Assisting, or Arranging follow-up (e.g. 77\% always Ask smoking status; 17\% always Arrange follow-up). Three 5 As factors were identified- 'Helping', 'Assessing quitting' and 'Assessing dependence'. Responses to barrier/enabler items showed greater knowledge, skills, intentions, and confidence with Assessment than Assisting; endorsement for SCS as a priority and part of midwives' professional role; and gaps in training and organisational support for SCS. Nine barrier/enabler factors were identified. Of these, the factors of 'Capability' (knowledge, skills, confidence); 'Work Environment' (service has resources, capacity, champions and values SCS) and 'Personal priority' (part of role and a priority) predicted 'Helping'.
\end{abstract}

Conclusion: The TDF enabled systematic identification of barriers to providing SCS, and the multivariate models identified key contributors to poor implementation. Combined with qualitative data, these results have been mapped to intervention components to develop a comprehensive intervention to improve SCS.

Keywords: Smoking cessation, Antenatal care, Theoretical domains framework, Health professional behaviour

\footnotetext{
* Correspondence: megan.passey@sydney.edu.au

'The University of Sydney, University Centre for Rural Health, PO Box 3074, Lismore, NSW 2480, Australia

Full list of author information is available at the end of the article
}

C C The Author(s). 2020 Open Access This article is licensed under a Creative Commons Attribution 4.0 International License, which permits use, sharing, adaptation, distribution and reproduction in any medium or format, as long as you give appropriate credit to the original author(s) and the source, provide a link to the Creative Commons licence, and indicate if changes were made. The images or other third party material in this article are included in the article's Creative Commons licence, unless indicated otherwise in a credit line to the material. If material is not included in the article's Creative Commons licence and your intended use is not permitted by statutory regulation or exceeds the permitted use, you will need to obtain permission directly from the copyright holder. To view a copy of this licence, visit http://creativecommons.org/licenses/by/4.0/. The Creative Commons Public Domain Dedication waiver (http://creativecommons.org/publicdomain/zero/1.0/) applies to the data made available in this article, unless otherwise stated in a credit line to the data. 


\section{Background}

Smoking is the single most important preventable cause of adverse infant outcomes including stillbirth, preterm birth, low birth weight, asthma, childhood respiratory infections and adult cardiovascular disease [1-4]. These harms are significantly reduced if women stop smoking during pregnancy [2]. Many pregnant women are highly motivated to quit smoking, but often face significant challenges in doing so, including lack of support from health professionals [5]. Psychosocial interventions to support pregnant women to quit are effective [2].

In Australia, clinical guidelines recommend routine and repeated assessment of smoking status for all pregnant women with ongoing support for quitting and staying quit, using the evidence-based 5As framework (Ask, Advise, Assess, Assist and Arrange follow-up) [6]. This means that, at every antenatal visit, the woman should be Asked her smoking status. If she is a current smoker, or has recently quit smoking, the remaining As are provided, as relevant. The woman should be Advised that the best thing she can do for her baby is to stop smoking, with discussion of the benefits of doing so. Her nicotine dependence and willingness to quit should be Assessed. She should then be Assisted, for example, encouraging her to stop smoking using motivational interviewing techniques, and providing resources and referral, as appropriate. Finally, the clinician should Arrange follow-up to provide additional support and monitor progress [6]. The 5As framework is effective, considered to be best practice and widely adopted in policy and practice both in Australia and internationally $[7,8]$. However, implementation of the 5 As continues to be poor with many women not provided with assistance for quitting $[9,10]$. In New South Wales (NSW), only $46 \%$ of women who smoked in pregnancy recalled being told about quitting programs [11]. Qualitative research has confirmed gaps in care, especially with Assisting and Arranging follow-up [12]. The failure to deliver smoking cessation support (SCS) is a critical missed opportunity to support cessation.

Changing the practice of health care providers requires the use of a comprehensive theory-driven and evidencebased approach which addresses specific behaviours in context [13]. One such approach, the 'Behaviour Change Wheel' (BCW), has demonstrated effectiveness in changing healthcare delivery [14]. The BCW approach starts with identification of the target behaviour for change, then development of a clear understanding of the barriers to its implementation. The $\mathrm{BCW}$ categorises barriers to implementing behaviours under three main constructs: Capability (Psychological or physical ability to enact the behaviour, e.g. having the required skills and knowledge); Opportunity (Physical and social environment that enables the behaviour, e.g. having the required resources to undertake the behaviour); and Motivation (Reflective and automatic mechanisms that activate or inhibit the behaviour, e.g. perceiving the behaviour as an important part of their role) [14]. Once the barriers to the behaviour have been identified and understood, the intervention is developed by mapping the identified barriers to intervention functions and behaviour change techniques [14]. Further detail on this process can be found in 'The Behaviour Change Wheel: A Guide to Designing Interventions'. [14].

The Theoretical Domains Framework (TDF) is a validated, comprehensive framework for identifying barriers and enablers to implementation [15] and can be used in the initial 'diagnostic' phase of the $\mathrm{BCW}$ process. The TDF was validated with 37 experts in behaviour change theory, using closed and open sort tasks with testing of the extent of replication by discriminant content validation and fuzzy cluster analysis [15]. It covers 14 domains of theoretical constructs (Knowledge, Skills, Memory, Attention and Decision Processes, Beliefs about Capabilities, Beliefs about Consequences, Optimism, Intentions, Goals, Emotion, Professional Role and Identity, Social Influences, Environmental Context and Resources, Behavioural Regulation, and Reinforcement) [15]. The TDF has previously been used to identify barriers to implementation, including barriers to providing SCS to women [16], with subsequent development of an effective intervention [17].

The objective of this paper is to examine the association between midwives' self-reported implementation of the 5As and reported barriers and enablers to their implementation, in order to identify critical areas for interventions designed to increase provision of SCS.

\section{Methods}

A cross-sectional on-line anonymous survey of midwives providing antenatal care in the public health system in NSW, Australia, was undertaken over 4 weeks in late 2016. Ethical approval was provided by the Hunter New England Human Research Ethics Committee (Ref. 14/ 06/18/5.04).

\section{Questionnaire development}

An initial draft questionnaire was developed based on the 14 domains of the TDF [15] and a review of literature and other instruments using the TDF $[14,16,18]$. The questionnaire also included items assessing provision of each of the 5As. These items were adapted from those used by Jordan et al [19], in order to reflect the NSW Guidelines for smoking cessation support during pregnancy [6] and asked about how often each of the 5 As was undertaken. These items were specifically designed to provide most emphasis on Assisting as this was identified as a critical gap in the literature. Items covering professional characteristics and personal 
smoking status were also included (see below under questionnaire content for details).

The questionnaire was assessed for face and content validity by five midwives with extensive experience in antenatal care and by a behavioural scientist with expertise in the use of the TDF. Face validity assesses whether an instrument appears to assess the desired qualities, and content validity assesses whether it covers all the important domains - both are subjective assessments [20]. The reviewers confirmed the comprehensiveness, acceptability and relevance of the items, with minor suggestions for improvements. In response to these suggestions, further refinements were made, with minor changes to wording for clarity, the addition of two items, reordering to reflect order of activities in antenatal care, and the reallocation of two items to different domains (one from 'goals' to 'beliefs about capabilities' and one from 'goals' to 'environmental context and resources'). The response format was well received and considered easy to follow and use. It was recommended to keep it as short as possible while covering key constructs, to maximise completion by busy midwives. The revised questionnaire was again reviewed by two of the five midwives, with final minor adjustments made to the ordering of items.

\section{Questionnaire content}

The final questionnaire contained 59 items, covering professional characteristics (five items), perceived barriers and enablers to providing the 5As (41 items), reported provision of the 5As (12 items) and participants' smoking status (one item).

Professional characteristics included years of midwifery experience, all models of antenatal care the respondent was currently working in, main model currently working in, annual number of births in their service and which Local Health District (LHD) they worked in.

Barriers and enablers covered all 14 TDF domains. A 5-point Likert scale response format was used, from strongly agree (score 1 ) to strongly disagree (score 5).

Respondents were asked to indicate the frequency with which they undertook each of the 5As. A 5-point Likert scale response format was used, from always (score 1) to never (score 5).

Smoking status response options were: I smoke every day; I smoke occasionally, but not every day; I'm an exsmoker, I never smoke now; I have never smoked.

The questionnaire was administered in REDCap, a secure application for managing online surveys and databases. The questionnaire took less than $15 \mathrm{~min}$ to complete and was anonymous, thus ensuring confidentiality for participants. It is available in Additional file 1.

\section{Participants and recruitment}

As we were interested in developing an intervention to improve implementation of the 5As during pregnancy across NSW, we wanted to include all midwives providing antenatal care in the NSW Public Health system, rather than focus on just one area or facility. The NSW Public Health system is administered through 15 LHDs. All LHDs were invited to participate, and participants were eligible if they were a midwife currently providing antenatal care in any of these LHDs. Eligible midwives were invited to participate by Clinical Midwifery Consultants (CMCs) in 14 of the 15 NSW LHDs, with one LHD not participating. CMCs are senior midwives whose role includes development of policy and strategy to ensure high quality care, including support for research to improve care. The project had been discussed and endorsed by the CMC network, with agreement to distribute the online link to eligible midwives. The CMCs were sent an email script to invite midwives and asked to distribute to all eligible midwives in their district. Three reminders were sent to CMCs and the survey was open for 4 weeks. An incentive of AUD300 for use for professional development was offered to the LHD with the greatest proportion of eligible midwives participating (CMCs provided data on the number of eligible midwives each had invited).

\section{Analysis}

Data were analysed in SPSS (version 22) by a biostatistician (MR). Descriptive summary statistics were generated for all items.

Prior to assessing the associations between provision of the 5As and the barriers and enablers to their implementation, we undertook two separate factor analyses one to identify the constructs underlying the provision of the $5 \mathrm{As}$, and one to identify constructs underlying the barriers/enablers. This was done in order to reduce the number of tests required to assess the associations between the provision of the 5As and the barriers/enablers, thus reducing the risk of type 1 error. The factor analyses also facilitated assessment of the construct validity of the instrument.

Anti-imaging correlation matrix, Bartlett's test of sphericity and measure of sampling adequacy were used to identify the appropriateness of using factor analysis. Principal axis factoring (as we expected latent constructs) using the correlation matrix with both oblique (promax) and orthogonal (varimax) rotations were investigated. Factors with eigenvalues greater than 1 were extracted. For the oblique rotation, both the factor pattern matrix and the factor structure matrix were assessed. Negatively worded items were reverse coded. For the barriers/enablers analysis, due to paucity (none or one) of responses in the extreme 'Strongly disagree' category 
for 20 of the 41 items, the responses 'disagree' and 'strongly disagree' were combined, resulting in a four category Likert scale. The subsequent factor analysis using these responses on 41 items exhibited convergence problems, which were resolved by the exclusion of a single item. The excluded item 'I have good knowledge of the harms of smoking' had 98.5\% responses with either 'strongly agree' or 'agree' providing minimal discrimination. Cronbach's alpha $(>0.7)$, item-to-item $(>0.3)$ and item to total $(>0.5)$ correlations were used to assess adequate reliability or internal consistency of resultant factors. For all factors, variable items were coded such that higher scores indicated more frequent or optimal responses with multi-item factor composite scores being calculated as the mean of the items.

Associations between the resultant 5 As factors and the barrier/enabler factors were then assessed using general linear model techniques with each of the 5 As factors as dependent variables, and the barrier/enabler factors (continuous variables), midwives' smoking status ('never smoked', 'ever smoked' (current or past smokers)); and midwifery years of experience (' $0-5$ years', ' $6-10$ years', ' $11-15$ years' and $\geq 16$ years) as explanatory categorical variables. The interaction between smoking status and years of experience was also investigated. Univariate analyses were conducted prior to developing multivariate models. A backward stepwise process was used to determine which barrier/enabler factors contributed significantly to each of the 5A factors. All barrier/enabler factors as well as midwife smoking status and years of experience (as potential confounders) were included, then the least significant one excluded in a stepwise manner until all retained explanatory variables were significant $(p<0.05)$.

\section{Results}

\section{Respondent characteristics}

Of 750 midwives invited, 150 completed the questionnaire, giving a response rate of $20.0 \%$. Midwives reported a broad range of models of antenatal care, service size and years of service (Table 1). The majority (63\%) reported never smoking and one third were ex-smokers, with a small number reporting current smoking.

\section{Self-reported provision of $5 \mathrm{As}$}

Respondents more commonly reported Asking and Assessing than Advising, Assisting, or Arranging followup, although Assessing at subsequent visits was also less common (Fig. 1).

\section{Constructs underlying implementation of the 5As}

Factor analysis of the 5As responses identified three composite factors, representing three underlying constructs, with eigenvalues $>1$, explaining $63.5 \%$ of the
Table 1 Respondent and service characteristics

\begin{tabular}{|c|c|c|}
\hline Characteristic & $n$ & $\%$ \\
\hline \multicolumn{3}{|l|}{ Model of antenatal care MOSTLY worked in } \\
\hline Midwife and GP Shared Care & 72 & 48 \\
\hline Midwifery group practice & 30 & 20 \\
\hline Obstetric-led & 26 & 17 \\
\hline Team midwifery & 13 & 9 \\
\hline Aboriginal Maternal and Infant Health Service & 8 & 5 \\
\hline Publically funded homebirth & 1 & 1 \\
\hline \multicolumn{3}{|l|}{ Size of Service (births per year) } \\
\hline$\leq 500$ births & 44 & 29 \\
\hline 501-2000 births & 36 & 24 \\
\hline$>2000$ births & 70 & 47 \\
\hline \multicolumn{3}{|l|}{ Number of years working in midwifery } \\
\hline $0-5$ years & 32 & 21 \\
\hline $6-10$ years & 17 & 11 \\
\hline $11-15$ years & 81 & 54 \\
\hline$>15$ years & 20 & 13 \\
\hline \multicolumn{3}{|l|}{ Smoking status } \\
\hline I smoke every day & 3 & 2 \\
\hline I smoke occasionally, but not every day & 3 & 2 \\
\hline I'm an ex-smoker - I never smoke now & 48 & 32 \\
\hline I have never smoked & 95 & 63 \\
\hline Missing & 1 & 1 \\
\hline
\end{tabular}

variance. Factor 1 (named 'Helping'), included the Advise item, the five Assist items and the Arrange follow-up item. Factor 2 (named 'Assessing quitting') included the Ask item and the two Assess readiness items. Factor 3 (named 'Assessing dependence') included the two Assess nicotine dependence items. The factors, their loadings from the pattern matrix and Cronbach's alpha values are shown in Additional file 2.

\section{Reported barriers and enablers to provision of $5 \mathrm{As}$}

Consistent with responses regarding the provision of the 5As, responses to items about barriers and enablers showed greater knowledge, skills, intentions, and confidence with Assessing than with Assisting. Responses indicated endorsement by midwives for supporting smoking cessation as an important priority and part of their professional role. However, responses also indicated considerable gaps in training and organisational support for SCS. Full responses are provided in Additional file 2.

\section{Constructs underlying barriers and enablers}

The factor analysis identified nine factors with eigenvalues $>1$ from the 40 barriers/enablers items, explaining $66.5 \%$ of the total variance. There were seven composite factors with Cronbach's alpha statistics $>0.7$ confirming 


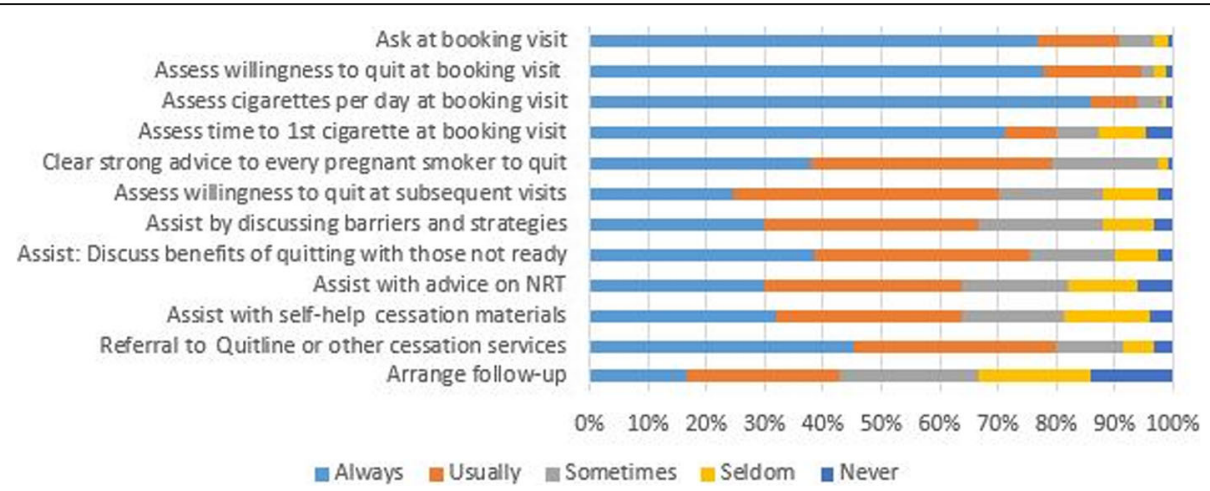

Fig. 1 Reported frequency of implementing the 5As

internal consistency and two single item factors. The first factor ('Capability') explained 32\% of the variance, and the first four factors explained over $50 \%$ of the total variance. The factor structure had clear conceptual coherence. The factors, their loadings from the pattern matrix and Cronbach's alpha values are shown in Table 2. Mean scores for each factor are shown in Fig. 2.

\section{Association between barriers and self-reported provision of the $5 \mathrm{As}$}

Associations between the 5As factors 'Helping' and 'Assessing quitting' and the explanatory variables (nine barrier/enabler factors) and potential confounders (smoking status and years of experience) were assessed using univariate general linear modelling. All associations were statistically significant with two exceptions the association of 'Helping' with 'Main things' and the association of 'Assessing quitting' with 'Quitline'. Higher scores on each of the barrier/enabler factors were associated with provision of higher levels of 'Helping' and 'Assessing quitting' and ever smokers provided higher levels of support than never smokers. As there was little variability in 5As Factor 3 ('Assessing dependence') we did not assess associations of explanatory variables with this factor.

The final multivariate models for 'Helping' and 'Assessing quitting' are shown in Table 3. Midwives who more strongly agreed with the items in the 'Capability', 'Work environment' and 'Personal priority' factors reported higher levels of 'Helping' actions. The important barrier factors for 'Assessing quitting' were somewhat different, with 'Intentions and memory', 'Work environment', 'Negative perceptions' (disagreeing) being significantly associated. Ever smokers provided higher levels of support than never smokers.

\section{Discussion}

In this paper we have assessed midwives self-reported provision of SCS to pregnant women, explored their perceptions of the barriers and enablers to providing this support and examined the relationship between these barriers and enablers and the support provided. This allowed identification of the most critical barriers and enablers that need to be addressed to improve delivery of effective SCS. Importantly, in developing our questionnaire, we used a comprehensive and validated theoretical framework, the TDF, which will facilitate the process of identifying intervention components using the $\mathrm{BCW}$ process [14]. The factor analyses of the two main components of the questionnaire identified three 5 As factors and nine barrier/enabler factors with the factors in each analysis explaining approximately two thirds of the variance, all composite factors having high Cronbach's alpha, and the structures having conceptual coherence, thus providing evidence for the validity of the questionnaire.

Asking and Assessing (especially nicotine dependence) were more commonly performed than Advising, Assisting and Arranging follow-up, and smoking was more commonly addressed at the initial visit than subsequent antenatal visits (Fig. 1). By contrast, other studies have found that Asking smoking status and giving brief Advice to quit smoking were more commonly performed than Assessing, providing Assistance or Arranging follow-up [19, 21-24]. In the case of provision of advice, this difference may result from the wording of our question ('How often do you give clear, strong messages urging every pregnant smoker to quit?'). Most other studies have asked about providing 'brief advice' which may account for the higher positive response. Chang et al audio-recorded 116 interactions at the first obstetric visit and identified that obstetricians Asked about smoking in $98 \%$ of visits but only provided Advice to quit in $31 \%$ of visits. In only six of the 116 cases was the Advice considered to be 'strong' advice, and in only four cases was it 'clear, strong and personalised'. [25].

The high rate of Assessing nicotine dependence is likely due to the clinical information system used by 
Table 2 Factor categories and loadings for the barriers/enablers of implementation of the $5 \mathrm{As}$

\begin{tabular}{|c|c|c|}
\hline $\begin{array}{l}\text { Factor } \\
\text { (Cronbach's alpha) }\end{array}$ & Item & Loading \\
\hline \multirow[t]{12}{*}{ Capability (0.927) } & I have good knowledge of the use of NRT in pregnancy & .863 \\
\hline & I have good skills in assisting pregnant women who are struggling to quit & .795 \\
\hline & I have good skills in assisting pregnant women with strategies to quit smoking & .776 \\
\hline & I have the skills required to determine and interpret pregnant women's nicotine dependence & .774 \\
\hline & I know how to provide smoking cessation support in antenatal care to help pregnant women quit & .768 \\
\hline & I have good knowledge of nicotine addiction and the barriers to quitting smoking & .761 \\
\hline & I am confident providing smoking cessation assistance to pregnant women & .751 \\
\hline & I am confident assessing women's smoking status & .721 \\
\hline & I am confident arranging follow-up support for pregnant smokers & 631 \\
\hline & I've had adequate training in assisting pregnant women to quit smoking & .584 \\
\hline & I have good skills in motivating pregnant women who don't want to quit, to try to quit & .583 \\
\hline & $\begin{array}{l}\text { I am familiar with the guidelines for using the } 5 \text { As for smoking cessation during antenatal care } \\
\text { (Ask, Advise, Assess, Assist, Arrange Follow-up) }\end{array}$ & .497 \\
\hline \multirow[t]{5}{*}{ Intentions and memory (0.826) } & I intend to provide smoking cessation support to each pregnant smoker & .878 \\
\hline & I intend to follow up with all smokers about their smoking at later visits (after the booking in visit) & .810 \\
\hline & I always remember to advise women who smoke to quit smoking & 689 \\
\hline & I intend to advise all pregnant smokers to quit & .612 \\
\hline & I always remember to provide smoking cessation support to smoking women at every antenatal visit & .519 \\
\hline \multirow[t]{5}{*}{ Work environment (0.796) } & Our service has good pamphlets and resources to support pregnant smokers to quit & .965 \\
\hline & Our service has capacity to provide smoking cessation support for pregnant smokers & .739 \\
\hline & $\begin{array}{l}\text { Our service has midwives, obstetricians and/or managers who really champion addressing smoking } \\
\text { with our clients }\end{array}$ & .611 \\
\hline & The clinic I work in values midwives who follow the 5 As guidelines & .554 \\
\hline & The team I work with places a high priority on addressing smoking with pregnant women & .457 \\
\hline \multirow[t]{5}{*}{ Emotional reward (0.767) } & Helping women quit smoking makes me feel proud of my role & .778 \\
\hline & I get satisfaction from providing smoking cessation support to pregnant women & .591 \\
\hline & I think providing smoking cessation support for pregnant women increases the chances that they'll quit & .584 \\
\hline & I feel optimistic that providing smoking cessation support helps women quit smoking & .488 \\
\hline & Most women appreciate it when I discuss quitting smoking with them & .361 \\
\hline \multirow[t]{6}{*}{ Negative perceptions $(0.720)$} & I often find talking with pregnant smokers about their smoking makes me feel uncomfortable & .715 \\
\hline & Advising women to quit smoking risks pushing them away from antenatal care & .704 \\
\hline & $\begin{array}{l}\text { After the booking in visit, providing smoking cessation support is not as important to me as } \\
\text { providing some other aspects of antenatal care }\end{array}$ & .461 \\
\hline & I don't have time to provide smoking cessation support in visits after the booking in visit & .453 \\
\hline & The harms of smoking in pregnancy are not as great as the other risks that women face & .426 \\
\hline & Providing smoking cessation support to women is not worth it given the small level of success & .377 \\
\hline \multirow[t]{3}{*}{ Personal priority (0.782) } & Providing smoking cessation support for pregnant women is an important part of my role & .752 \\
\hline & Talking with women about quitting smoking is a good use of my time & .528 \\
\hline & I place a high priority on helping women quit smoking & .406 \\
\hline \multirow[t]{2}{*}{ Tracking systems (0.84) } & $\begin{array}{l}\text { I have systems in place (e.g. a checklist or stickers) to help me keep track of women who smoke } \\
\text { and provide ongoing smoking cessation support for them }\end{array}$ & .936 \\
\hline & $\begin{array}{l}\text { Our service has systems in place to help keep track of women who smoke and provide ongoing } \\
\text { support for them }\end{array}$ & .574 \\
\hline Main things & $\begin{array}{l}\text { Advising women to quit smoking is one of the main things that can be done to help women } \\
\text { have healthy babies }\end{array}$ & .328 \\
\hline Quitline & Referring women to the Quitline is an effective way of assisting pregnant women to quit & .496 \\
\hline
\end{tabular}




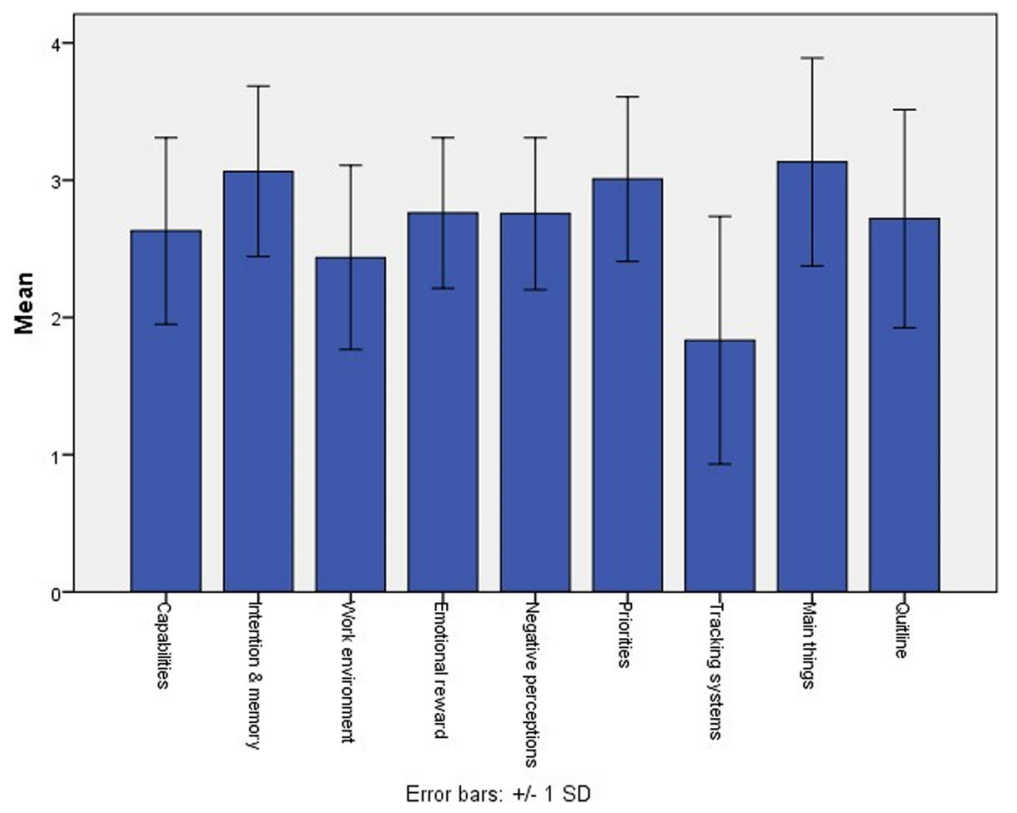

Fig. 2 Mean scores for barrier/enabler factors

midwives, which made assessment of nicotine dependence (time to first cigarette and cigarettes/day) mandatory fields for all smokers. The inclusion of these mandatory fields in the clinical information system also explains the lack of variability in response to these questions and highlights the importance of electronic information systems in providing prompts for clinical activity [26].

.The finding that smoking is more frequently addressed at the initial visit than at subsequent visits is consistent with multiple other studies with both midwives and obstetricians [12, 22, 24, 27, 28]. Offering personalised support for cessation repeatedly throughout pregnancy is valuable as it provides a consistent message for women that midwives are concerned about them and their smoking $[29,30]$.

.The factor analysis of the 5As questions identified three factors, with one main factor (named 'Helping') including all the Advice, Assist and Arrange follow-up items, with strong factor loadings (all $>0.58$ ). The other two factors, 'Assessing Quitting' and 'Assessing Dependence', related to assessing women's behaviour. While making assessments is useful for clinicians' understanding of the woman's dependence and attitudes, they provide no support to the woman for an actual quit attempt. Unfortunately, although it is Assisting and Arranging follow-up that are critical to successful

Table 3 Multivariate models of the association between 'Helping' and 'Assessing quitting' and the barriers/enablers factors

\begin{tabular}{|c|c|c|c|c|c|c|c|c|}
\hline \multirow[t]{3}{*}{ Adjusted $R^{2}$} & \multicolumn{4}{|c|}{ 'Helping' } & \multicolumn{4}{|c|}{ 'Assessing quitting' } \\
\hline & \multicolumn{4}{|l|}{0.431} & \multicolumn{4}{|l|}{0.298} \\
\hline & $\mathrm{F}$ & $\beta$ & SE & $p$ & $\mathrm{~F}$ & $\beta$ & SE & $p$ \\
\hline Model $p$ value & & & & $<0.001$ & & & & $<0.001$ \\
\hline \multicolumn{9}{|l|}{ Barriers/enablers constructs } \\
\hline Capability (1) & 9.36 & 0.304 & 0.099 & 0.003 & & & & \\
\hline Intentions \& memory (2) & & & & & 9.26 & 0.263 & 0.086 & 0.003 \\
\hline Work environment (3) & 16.04 & 0.379 & 0.095 & $<0.001$ & 4.19 & 0.159 & 0.077 & 0.042 \\
\hline Negative perceptions (5) & & & & & 11.62 & 0.313 & 0.092 & 0.001 \\
\hline Personal priority (6) & 8.09 & 0.283 & 0.099 & 0.005 & & & & \\
\hline \multicolumn{9}{|l|}{ Personal characteristics } \\
\hline Smoking status & 6.20 & & & 0.014 & 10.31 & & & 0.002 \\
\hline
\end{tabular}

Note: Each of the variables in the final models account for $1 \mathrm{df}$ (error $\mathrm{df}=145$ ) 
quitting [31-33], ,the items in the 'Helping' factor were least likely to be performed ('Always' performed by 30 to $45 \%$ of survey respondents).

The first factor identified in the analysis of barriers was 'Capability', which included all the knowledge, skills and confidence (beliefs about capabilities) items. Participants reported poorer knowledge, skills and confidence related to Assisting than Assessing, and more commonly agreed with knowledge statements than with those for skills and confidence - consistent with both their reported behaviour and other research [12, 21, 22]. Importantly, the 'Capability' factor was significantly associated with 'Helping' women, and thus, ascertaining the items in 'Capability' with lesser agreement (skills, confidence and adequate training) helps to identify potential components for interventions. Skills training for health professionals improves professional performance and continuous abstinence [34].

.The 'Work Environment' factor was significantly associated with both 'Helping' and 'Assessing quitting'. There was considerable spread in the responses to the items included in 'Work Environment', although there was greater agreement with the items related to capacity of the service and pamphlets and resources, than those related to values and social influence. The item with the lowest agreement related to champions within the service, suggesting that developing local cessation champions would be beneficial [35]. Champions may impact the culture of the organisation, motivating other staff, supporting staff training, and monitoring service provision and client outcomes [35].

.The 'Personal priority' factor was also associated with 'Helping'. There was little disagreement with any of the three items in this factor, however, the item about placing a high priority on smoking cessation was least well supported. Qualitative research has identified that a perceived lack of time to address smoking, combined with a perception that smoking was a 'private' issue resulted in smoking cessation being a low priority in some circumstances [12]. One approach to persuading clinicians to prioritise smoking cessation is to 'reframe' their perception of smoking by drawing parallels with other conditions and their approach to them [14]. This could involve education about the comparative health consequences of different problems (e.g. smoking vs diabetes), combined with a comparison of the clinical responses and management of each.

The 'Intentions and Memory' factor was also important in predicting 'Assessing quitting'. There was stronger agreement with intentions than remembering, with lesser agreement for intentions and memory after the first visit. This suggests that prompts and reminders could be beneficial, particularly focused on subsequent visits - either in the form of enhanced electronic reminders or required fields, or other aids such as flowcharts and clinical pathways displayed in the clinic. As discussed earlier, the high rate of assessment of nicotine dependence identified in this study is likely due to design features of the clinical information system in use.

The final factor significantly related to 'Assessing quitting' was 'Negative perceptions'. These items were reverse coded, indicating that stronger disagreement with these statements was associated with greater assessment of interest in quitting smoking. It is not surprising that a perception that supporting smoking cessation is difficult and not likely to be successful is associated with lesser assessment of interest in quitting. However, with adequate training, managerial support, provision of useful resources and referral options, this negative perception may be changed.

\section{Limitations}

Despite considerable efforts to maximise response rates, including engaging with the CMC network prior to the survey, using this network to recruit midwives, sending repeated reminders and offering an incentive for participation, the response rate was low. Response rates among health professionals are often low, (25\% of American obstetrician-gynecologists [27], and only 6\% of Australian physicians [21] responded to similar surveys) and the strategies we implemented are recommended for maximising recruitment [36]. The low response rate is therefore particularly disappointing and the respondents cannot be considered representative of all midwives providing antenatal care in the NSW Health system. However, the objective of this paper was to examine the relationship between perceived barriers and reported provision of support and this internal analysis remains valid as a study's population does not need to be representative of the population from which it is derived in order to validly ascertain relationships of interest [3739]. A further limitation is that we relied on self-report of provision of SCS, and there is likely some overreporting, although the anonymous nature of the survey may have facilitated honest responses. Nonetheless, consistent with other studies, there were many fewer respondents reporting Assisting and Arranging followup, suggesting minimal over-reporting.

\section{Conclusions}

In this study, respondents more commonly reported Asking and Assessing than Advising, Assisting, or Arranging follow-up. Three 5As factors were identified- 'Helping', 'Assessing quitting' and 'Assessing dependence'. Responses to barrier/enabler items showed greater knowledge, skills, intentions, and confidence with Assessment than Assisting; endorsement for SCS as a priority and part of midwives' professional role; and gaps in training and 
organisational support for SCS. Nine barrier/enabler factors were identified. Of these, the factors of 'Capability'; 'Work Environment' and 'Personal priority' predicted 'Helping'.

The use of the TDF enabled a systematic and comprehensive approach to identifying barriers to providing SCS, and the multivariate models allowed assessment of the main contributors to poor implementation. This process, including the use of the TDF, facilitates mapping barriers to intervention components using the BCW [14]. Combined with qualitative data already published [12], these results have been mapped to specific, tailored intervention components and behaviour change techniques to form a comprehensive intervention to improve implementation of SCS.

\section{Supplementary information}

Supplementary information accompanies this paper at https://doi.org/10. 1186/s12884-020-02912-0.

Additional file 1. is a pdf file containing the questionnaire used in the study.

Additional file 2 Table S1. presents the Factor loadings, Cronbach's alpha and correlations for the factor analysis of provision of the 5As from the Pattern matrix. Table S2. presents the data on the frequency of responses to questions on the barriers and enablers to providing the $5 \mathrm{As}$.

\section{Abbreviations}

5As: Ask, Advise, Assess, Assist, Arrange follow-up; BCW: Behaviour change wheel; CMC: Clinical midwifery consultant; LHD: Local health district; SCS: Smoking cessation support; TDF: Theoretical domains framework

\section{Acknowledgements}

The authors thank the members of the project Advisory Group for their support and advice throughout the study: Clair Ramsden, Kate Williams, Peter Bland, Vanessa Clements, Rhonda Matthews, Julie Dorling and Ros Tokley.

\section{Authors' contributions}

MP initially conceived the study. MP, JL and CA contributed to study design and development. MP, JL, CA, JJ, JS and MR all contributed to study implementation and data collection. MP and MR analysed the data. MP drafted the initial manuscript. MP, JL, CA, JJ, JS and MR all contributed to manuscript revisions and approved the final manuscript.

\section{Funding}

This work was supported by the National Health and Medical Research Council of Australia (GNT1072213 to MP) and the Cancer Institute New South Wales (13/ECF/1-11 to MP). The funding bodies played no role in the design of the study, or in the collection, analysis and interpretation of the data.

\section{Availability of data and materials}

The dataset used during the current study is available from the corresponding author on reasonable request.

\section{Ethics approval and consent to participate}

Ethical approval was provided by the Hunter New England Human Research Ethics Committee (Ref. 14/06/18/5.04). All participants provided consent to participate at the beginning of the online survey. The Participant Information Sheet was included as the first screen in the survey. Participants clicked on a button to indicate consent and were then directed to the questionnaire. This process was approved by the ethics committee.
Consent for publication

Not applicable.

\section{Competing interests}

The authors declare that they have no competing interests.

\section{Author details}

${ }^{1}$ The University of Sydney, University Centre for Rural Health, PO Box 3074, Lismore, NSW 2480, Australia. ${ }^{2}$ Northern New South Wales Local Health District, Locked Mail Bag 11, Lismore, NSW 2480, Australia.

Received: 12 January 2020 Accepted: 30 March 2020

Published online: 15 April 2020

\section{References}

1. British Medical Association. Smoking and reproductive life: the impact of smoking on sexual, reproductive and child health. London: British Medical Association; 2004

2. Chamberlain C, O'Mara-Eves A, Porter J, Coleman T, Perlen SM, Thomas J, et al. Psychosocial interventions for supporting women to stop smoking in pregnancy. Cochrane Database Syst Rev. 2017(2):Art. No.: CD001055. https:// doi.org/10.1002/14651858.CD001055.pub5.

3. Bakker $\mathrm{H}$, Jaddoe WW. Cardiovascular and metabolic influences of fetal smoke exposure. Eur J Epidemiol. 2011;26(10):763-70.

4. U.S. Department of Health and Human Services. The health consequences of involuntary exposure to tobacco smoke: a report of the surgeon general. Rockville: US Department of Health and Human Services; 2006.

5. Flemming K, McCaughan D, Angus K, Graham H. Qualitative systematic review: barriers and facilitators to smoking cessation experienced by women in pregnancy and following childbirth. J Adv Nurs. 2015;71(6): $1210-26$.

6. NSW Ministry of Health. Clinical guidelines for the management of drug use during pregnancy, birth and the postnatal period. Sydney: NSW Ministry of Health; 2014.

7. Fiore M, Jaén C, Baker T, Bailey W, Benowitz N, Curry SJ, et al. Treating tobacco use and dependence: 2008 update. Clinical practice guideline. Rockville: US Department of Health and Human Services, Public Health Service; 2008

8. Melvin $\mathrm{CL}$, Dolan-Mullen $\mathrm{P}$, Windsor RA, Pennington Whiteside $\mathrm{H} \mathrm{Jr}$, Goldenberg RL. Recommended cessation counselling for pregnant women who smoke: a review of evidence. Tob Control. 2000; 9(Supplement III):iii80-i4.

9. Perlen S, Brown SJ, Yelland J. Have guidelines about smoking cessation support in pregnancy changed practice in Victoria, Australia? Birth. 2013; 40(2):81-7.

10. Passey ME, Sanson-Fisher RW. Provision of antenatal smoking cessation support: a survey with pregnant aboriginal and Torres Strait islander women. Nicotine Tob Res. 2015;17(6):746-9.

11. Bureau of Health Information. Patient perspectives - experiences of maternity care in NSW public hospitals, January to December 2015. Sydney: Bureau of Health Information; 2017.

12. Longman JM, Adams CM, Johnston JJ, Passey ME. Improving implementation of the smoking cessation guidelines with pregnant women: what might help clinicians? Midwifery. 2018;58:137-44.

13. Baker R, Camosso-Stefinovic J, Gillies C, Shaw EJ, Cheater F, Flottorp S, et al. Tailored interventions to address determinants of practice. Cochrane Database Syst Rev. 2015(4):Art. No.: CD005470.

14. Michie S, Atkins L, West R. The behaviour change wheel: a guide to designing interventions: silverback; 2014.

15. Cane J, O'Connor D, Michie S. Validation of the theoretical domains framework for use in behaviour change and implementation research. Implement Sci. 2012;7:37.

16. Beenstock J, Sniehotta FF, White M, Bell R, Milne EM, Araujo-Soares V. What helps and hinders midwives in engaging with pregnant women about stopping smoking? A cross-sectional survey of perceived implementation difficulties among midwives in the north east of England. Implement Sci. 2012;7:36

17. Bell R, Glinianaia SV, Zvd W, Close A, Moloney E, Jones S, et al. Evaluation of a complex healthcare intervention to increase smoking cessation in pregnant women: interrupted time series analysis with economic evaluation. Tob Control. 2018;27:90-8. 
18. Hujig JM, Gebhardt WA, Crone MR, Dusseldorp E, Presseau J. Discriminant content validity of a theoretical domains framework questionnaire for use in implementation research. Implement Sci. 2014;9:11.

19. Jordan TR, Dake JR, Price JH. Best practices for smoking cessation in pregnancy: do obstetrician/gynecologists use them in practice? J Women's Health. 2006;15(4):400-41.

20. Streiner DL, Norman GR. Health measurement scales. A practical guide to their development and use. New York: Oxford University Press; 1989.

21. Bar Zeev Y, Bonevski B, Twyman L, Watt K, Atkins L, Palazzi K, et al. Opportunities missed: a cross-sectional survey of the provision of smoking cessation care to pregnant women by Australian general practitioners and obstetricians. Nicotine Tob Res. 2017;19(5):636-41.

22. Lemola S, Meyer-Leu Y, Samochowiec J, Grob A. Control beliefs are related to smoking prevention in prenatal care. J Eval Clin Pract. 2013;19(5):948-52.

23. Okoli CTC, Greaves L, Bottorff $\lrcorner$, Marcellus LM. Health care providers' engagement in smoking cessation with pregnant smokers. J Obstet Gynecol Neonatal Nurs. 2010;39(1):64-77.

24. Murphy K, Steyn K, Mathews C. The midwife's role in providing smoking cessation interventions for pregnant women: the views of midwives working with high risk, disadvantaged women in public sector antenatal services in South Africa. Int J Nurs Stud. 2016;53:228-37.

25. Chang JC, Alexander SC, Holland CL, Arnold RM, Landsittel D, Tulsky JA, et al. Smoking is bad for babies: obstetric care providers' use of best practice smoking cessation counseling techniques. Am J Health Promot. 2013;27(3):170-6.

26. Shojania KG, Jennings A, Mayhew A, Ramsay CR, Eccles MP, Grimshaw J. The effects of on-screen, point of care computer reminders on processes and outcomes of care. Cochrane Database Syst Rev. 2009(3):Art. No.: CD001096.

27. Coleman-Cowger VH, Anderson BL, Mahoney J, Schulkin J. Smoking cessation during pregnancy and postpartum: practice patterns among obstetrician-gynecologists. J Addict Med. 2014;8(1):14-24.

28. Tzelepis F, Daly J, Dowe S, Bourke A, Gillham K, Freund M. Supporting aboriginal women to quit smoking: antenatal and postnatal care providers' confidence, attitudes, and practices. Nicotine Tob Res. 2017;19(5):642-6.

29. Passey ME, Stirling JM. Evaluation of 'stop smoking in its tracks': an intensive smoking cessation program for pregnant aboriginal women incorporating contingency-based financial rewards. Public Health Res Pract. 2018;28(2): e28011804.

30. Bryce A, Butler C, Gnich W, Sheehy C, Tappin DM, Bryce A, et al. CATCH: development of a home-based midwifery intervention to support young pregnant smokers to quit. Midwifery. 2009;25(5):473-82.

31. Miller M, Wood L. Effectiveness of smoking cessation interventions: review of evidence and implications for best practice in Australian health care settings. Aust N Z J Public Health. 2003;27(3):300-9.

32. Quinn VP, Hollis JF, Smith KS, Rigotti NA, Solberg LI, Hu W, et al. Effectiveness of the 5-as tobacco cessation treatments in nine HMOs. J Gen Intern Med. 2009;24(2):149-54.

33. Park ER, Gareen IF, Japuntich S, Lennes I, Hyland K, DeMello S, et al. Primary care provider-delivered smoking cessation interventions and smoking cessation among participants in the National Lung Screening Trial. JAMA Intern Med. 2015;175(9):1509-16.

34. Carson KV, Verbiest EAM, Crone MR, Brinn MP, Esterman AJ, Assendelft JJW, et al. Training health professionals in smoking cessation. Cochrane Database Syst Rev. 2012(5):Art. No.: CD000214.

35. Santos L, Braun KL, Ae'a K, Shearer L. Institutionalizing a comprehensive tobacco-cessation protocol in an indigenous health system: lessons learned. Prog Community Health Partnersh. 2008;2(4):279-89.

36. Cho Yl, Johnson TP, VanGeest JB. Enhancing surveys of health care professionals:a meta-analysis of techniques to improve response. Eval Health Prof. 2013;36(3):382-407.

37. Banks E, Redman S, Jorm L, Armstrong B, Bauman A, Beard J, et al. Cohort profile: the 45 and up study. Int J Epidemiol. 2008;37:941-7.

38. Willett WC, Blot WJ, Colditz GA, Folsom AR, Henderson BE, Stampfer MJ. Merging and emerging cohorts: not worth the wait. Nature. 2007;445:257.

39. Longman JM, Bennett-Levy J, Matthews V, Berry HL, Passey ME, Rolfe M, et al. Rationale and methods for a cross-sectional study of mental health and wellbeing following river flooding in rural Australia, using a communityacademic partnership approach. BMC Public Health. 2019;19(1):1255.

\section{Publisher's Note}

Springer Nature remains neutral with regard to jurisdictional claims in published maps and institutional affiliations.

\section{Ready to submit your research? Choose BMC and benefit from:}

- fast, convenient online submission

- thorough peer review by experienced researchers in your field

- rapid publication on acceptance

- support for research data, including large and complex data types

- gold Open Access which fosters wider collaboration and increased citations

- maximum visibility for your research: over $100 \mathrm{M}$ website views per year

At BMC, research is always in progress.

Learn more biomedcentral.com/submissions 